\title{
Role of Methyl Radicals in the Growth of PAHs
}

\author{
Bikau Shukla, ${ }^{a}$ Akira Miyoshi, ${ }^{\mathrm{b}}$ and Mitsuo Koshi ${ }^{\mathrm{c}}$ \\ a National Institute of Advanced Industrial Science and Technology (AIST) Higashi Tsukuba, Japan \\ ${ }^{b}$ Department of Chemical System Engineering, The University of Tokyo, Tokyo, Japan \\ ${ }^{\mathrm{c}}$ Institute of Engineering Innovation, The University of Tokyo, Tokyo, Japan
}

The role of methyl radicals in the networking of $\mathrm{sp}^{2}$ carbons has been explored through kinetic analysis of mass spectra of the gas-phase products of the pyrolysis of toluene and toluene/acetone mixtures. Pyrolytic reactions were performed in a flow tube reactor at temperatures of $1140-1320 \mathrm{~K}$ and a constant total pressure of 10.38 Torr with a residence time of $0.585 \mathrm{~s}$. On addition of acetone, methyl substituted products and their derivatives were enhanced. Mass peaks were observed in several sequences at an interval of 14 mass units; these ions correspond to methyl substituted products formed as a result of hydrogen abstraction $(-\mathrm{H})$ followed by methyl radical addition $\left(+\mathrm{CH}_{3}\right)$. Each major peak was usually preceded by a peak at two mass units lower, which was likely produced through dehydrogenation/dehydrocyclization $\left(-\mathrm{H}_{2}\right)$ of methyl substituted products. Detected species include a large number of alkyl, cyclotetrafused (CT), cyclopentafused (CP) mono-, $\mathrm{di}-$, and polycyclic aromatic hydrocarbons (PAHs) along with primary PAHs. The analysis showed that MAC (methyl addition/cyclization) has a unique capacity to induce the sequential growth of hexagonal networks of $\mathrm{sp}^{2}$ carbons from all fusing sites [1] of a PAH. Moreover, MAC was found capable of answering an important question in PAH growth, which is expansion of the $\mathrm{CT} \rightarrow \mathrm{CP} \rightarrow$ hexagonal network for which other reported mechanisms are inefficient. (J Am Soc Mass Spectrom 2010, 21, 534-544) @ 2010 American Society for Mass Spectrometry

$\mathrm{T}$ The construction of a mechanism of soot formation for fuel oxidation and pyrolysis remains an interesting and challenging topic for combustion researchers. Soot formation is a very fast, complex process and it is not completely understood. There are four main factors impeding a better understanding of the sooting mechanism. The first is the reactions that are responsible for soot nucleation involve highly reactive species such as radicals that have a complicated chemistry. The second is the involvement of many competing reactions. The third is the existence of a large number of isomers, especially of PAHs, and the fourth is the unavailability of thermodynamic and kinetic parameters for the large number of neutral and radical species involved.

One of the popular mechanisms for the growth of PAHs under pyrolytic conditions is hydrogen abstraction and acetylene addition (HACA) [2-5], which has been found to be slow relative to the very fast process of $\mathrm{PAH}$ and soot formation [6, 7]. As an alternative fast process, Böhm et al. [6] proposed aromatic ring-ring condensation followed by a $\mathrm{C}_{2} \mathrm{H}_{2}$ addition mechanism. In addition, aryl-aryl combination followed by ring cyclization [8-11] and a particle filler model [12] were reported in other studies. Similarly, the condensation of an aromatic radical and neutral species was proposed

Address reprint requests to Dr. M. Koshi, Institute of Engineering Innovation, 2-11-16 Yayoi, Bunkyo-ku, Tokyo 113-8656, Japan. E-mail: koshi@ rocketlab.t.u-tokyo.ac.jp and Dr. B. Shukla, AIST, Central-5, 1-1-1 Higashi Tsukuba, Ibaraki, Japan. , cab_shukla@yahoo.com. by Unterreiner et al. [13]. Very recently, we have proposed a highly efficient phenyl addition/cyclization (PAC) mechanism [14] for the growth of large PAHs accelerated by the phenyl radical chain carrier. However, all these mechanisms have ignored the role of alkyl radicals in the formation of PAHs from alkylaromatic compounds, such as toluene present in fuels. Similar to acetylene, methyl radical is also produced significantly during pyrolysis and oxidation of most aliphatic and alkylaromatic hydrocarbons. On the basis of the substantial growth of a graphene layer by methyl radicals, Wellmann et al. [15] suggested that the influence of methyl radicals might also be significant in soot formation. From a literature review of the reactions of methyl radical with aromatic species and PAHs, it is found that studies have been generally limited to the reaction of methyl radical with toluene. Some papers [9, 16-18] have reported faster abstraction of $\mathrm{H}$ atom from the aromatic ring of toluene by methyl radical to produce $o$ - and $p$-xylenes, while other studies [19-21] have observed faster abstraction of $\mathrm{H}$ atom from the side chain to produce ethylbenzene. Unterreiner et al. [22] have reported the chemisorption of methyl radicals on large PAHs. However, the role of methyl radicals in $\mathrm{PAH}$ growth and soot formation has not yet been explored. Although methyl radical is an unstable species that reacts rapidly with other radicals and neutral species, its role in the formation of PAHs may be relevant to mechanisms of combustion. Moreover, methyl radical might be significantly influencing the 
chemical vapor deposition (CVD) growth of carbon nanotubes (CNTs) and "graphene," an important research area, since many groups have been synthesizing CNTs [23-25] and graphene [26, 27] from methane. In our previous study [1], the importance of methyl radicals in PAH growth was suggested. In the present study, we have explored this process in detail. Pyrolysis of toluene with and without addition of acetone was performed in a flow tube reactor, and the resulting gas-phase products were detected by using vacuum ultraviolet (VUV) single photon ionization (SPI) timeof-flight mass spectrometry (TOFMS). Acetone was selected as a methyl source due to its facile thermal decomposition.

\section{Experimental}

The details of the experimental setup have been described elsewhere [1]. Briefly, the apparatus consists of a quartz reaction tube wrapped with a tungsten heater placed into a source chamber aligned with the linear time of flight mass spectrometer (TOFMS). An ultraviolet (UV) laser pulse (355 nm) was loosely focused into the frequency tripling cell filled with xenon (pressure $=$ 7.41 Torr) to generate vacuum ultraviolet (VUV) photons at $118 \mathrm{~nm}(10.5 \mathrm{eV})$. The UV beam was separated and removed by a LiF crystal prism to avoid the $(1+1)$ ionization by $355 \mathrm{~nm}$ and $118 \mathrm{~nm}$ photons. Flows of $40 \%$ toluene with $60 \% \mathrm{He}$ or $20 \%$ toluene, $20 \%$ acetone, and
$60 \%$ He (by volume) were supplied into the reactor through the mass flow controllers. The gaseous products were continuously sampled through a pinhole and were collimated by a $1.0 \mathrm{~mm}$ orifice skimmer mounted $3.0 \mathrm{~mm}$ from the pinhole. The molecular beam was introduced into the ionization region of the TOFMS and the molecular species were ionized by the $118 \mathrm{~nm}$ photons. The ionized species were accelerated by the electrodes, lenses, and deflectors through the [fieldfree] drift tube to the MCP (multi-channel plate). Mass spectra were recorded at three different temperatures of $1140-1320 \mathrm{~K}$ and at a constant total pressure of 10.38 Torr with a constant residence time of $0.585 \mathrm{~s}$.

The occurrence of electron impact ionization by photoelectrons produced by stray light and the possibility of multi-photon ionization that may cause fragmentation were considered; these processes were ruled out by the absence of signal from species with ionization energies greater than $10.5 \mathrm{eV}$ and the absence of fragment ions. The laser power dependence was monitored to avoid fragmentation from multi-photon ionization.

\section{Results}

All observed mass peaks have been normalized with respect to VUV intensities observed at each temperature just before the sample introduction. Mass spectra of the products of pyrolysis of the toluene/acetone mixture

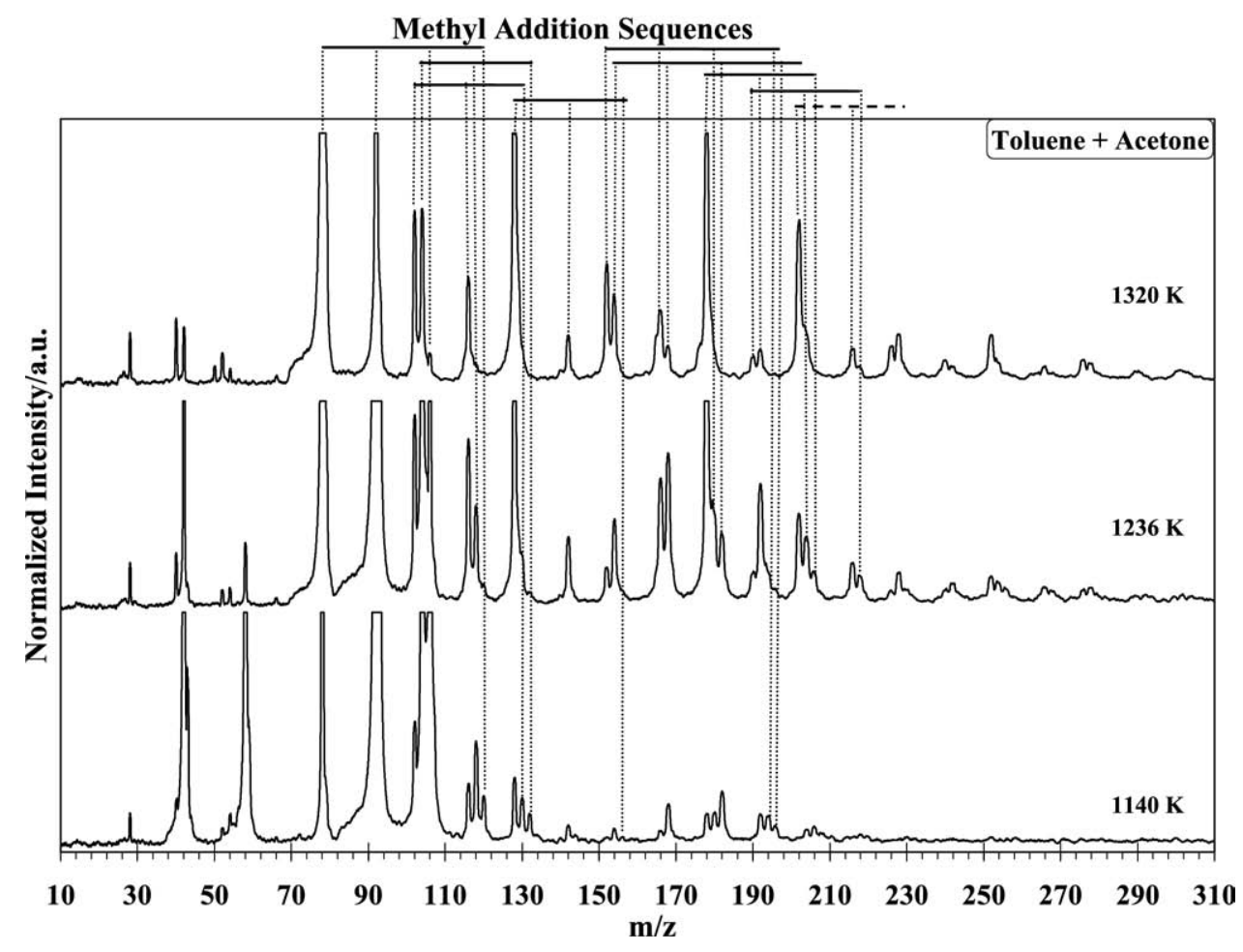

Figure 1. Typical TOF mass spectra of products of a toluene/acetone mixture at three different temperatures and a constant total pressure of 10.38 Torr with a residence time of $0.585 \mathrm{~s}$. These mass peaks have been normalized with respect to VUV intensities observed at each temperature just before the sample introduction. 
are shown in Figure 1. Generally, mass peaks appeared in bundles in which each successive peak differs from its closest former neighbor by two mass units $(2 \mathrm{u})$, indicating the corresponding species with the same number of carbons and two fewer hydrogen atoms. Mass peaks of methyl substituted products are found at the highest mass number and their derived dehydrogenated/dehydrocyclized products at consecutive $-2 \mathrm{u}$ in the same-carbon-number block of peaks. Also, compounds with smaller masses $(<78 \mathrm{u})$ were observed uniquely. From all possible candidates for a mass peak, the most probable identity has been assigned with the help of chemical kinetics, which will be discussed in detail in the discussion section.

\section{Changes in Mass Spectra on Addition of Acetone}

The mass spectra observed at three different temperatures in toluene/acetone pyrolysis are compared with those for toluene only in Figure 2, and the assignment of mass peaks is shown in Table 1. Identified mass numbers, especially for aromatic products, have been shown in the ladder-like Scheme 1. The addition of acetone significantly increases the intensities of ethylbenzene $(m / z=106)$ and its derived products by significantly depleting the intensity of bibenzyl $(\mathrm{m} / \mathrm{z}=$ 182). Moreover, a unique result is the appearance of mass peaks at regular intervals in sequential patterns as shown at the top of Figure 1 and below in Scheme 1.

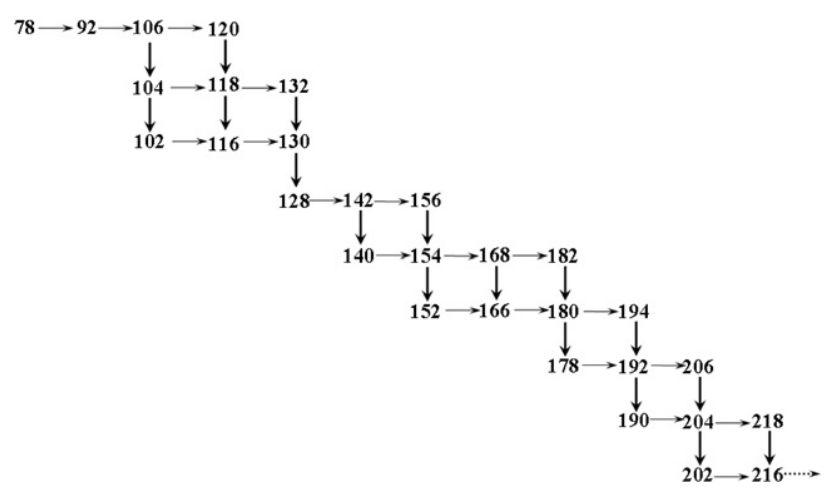

Scheme 1. Schematic representation of detected mass numbers. Horizontal arrows represent the regular increase in mass by $14 \mathrm{u}$ and downward vertical arrows represent the decrease in mass by $2 u$.

Particularly in the case of the toluene/acetone mixture, mass peaks appeared at equal intervals of mass $14 \mathrm{u}$ (horizontal arrows) followed by another similar sequence of mass peaks at $-2 \mathrm{u}$; these latter peaks either appear or become significant only at high temperatures (downward vertical arrows).

This scheme clearly shows the systematic growth of aromatic species from benzene $(\mathrm{m} / \mathrm{z}=78)$ to a PAH, pyrene $(m / z=202)$, and beyond. The most interesting feature is the regular growth by $14 \mathrm{u}$ that most probably corresponds to loss of $\mathrm{H}$ and addition of methyl radical, a chain accelerating species for the overall growth process.

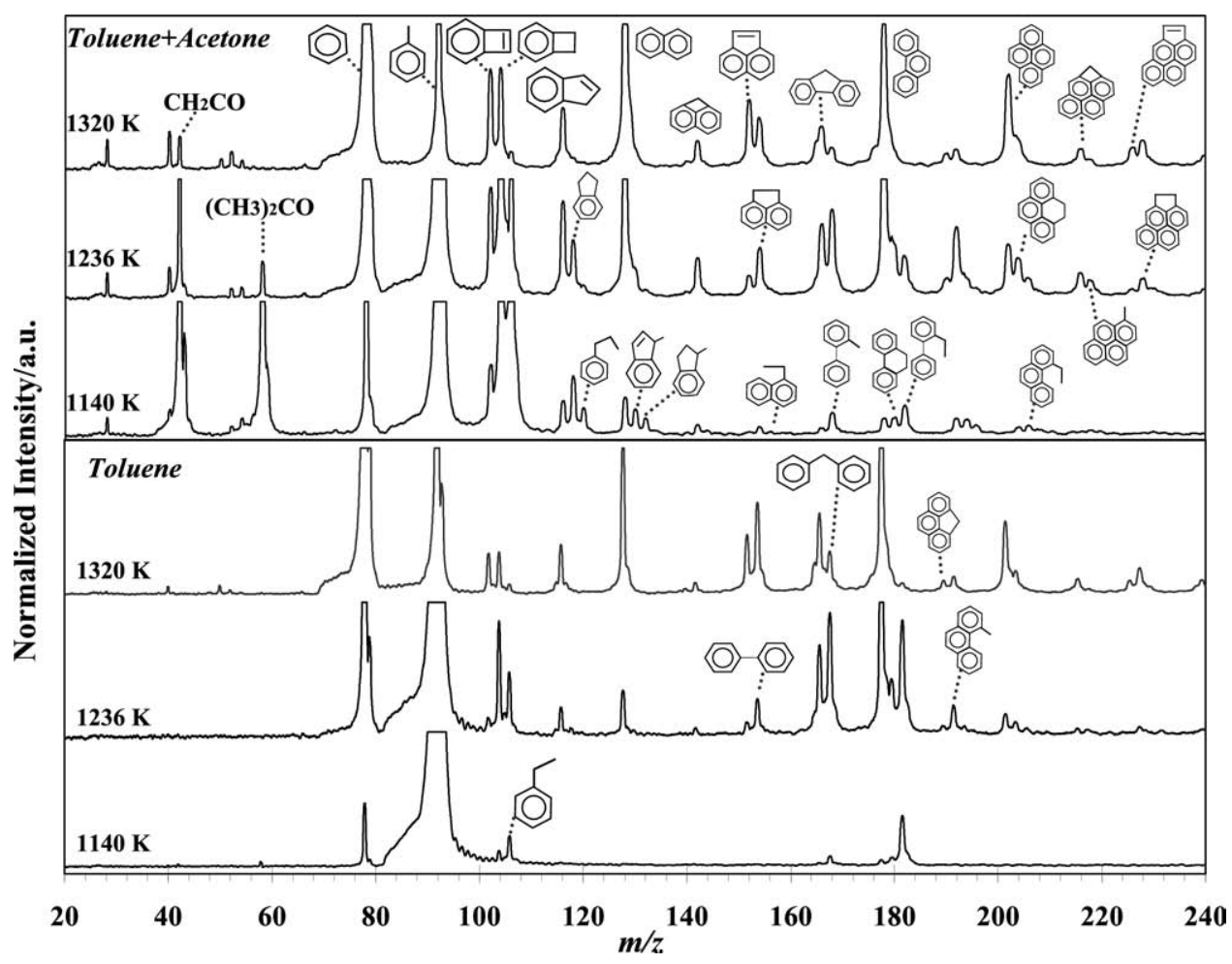

Figure 2. Comparison of TOF mass spectra of products of a toluene/acetone mixture and those of pure toluene recorded at three different temperatures and a constant total pressure of 10.38 Torr with a residence time of $0.585 \mathrm{~s}$. These mass peaks have been normalized with respect to VUV intensities observed at each temperature just before the sample introduction. 
Table 1. Species detected during the pyrolysis of a toluene/acetone mixture that were not produced in pure toluene (species produced in pure toluene can be seen in Shukla et al. [1].

\begin{tabular}{ll}
\hline $\mathrm{m} / \mathrm{z}$ & \multicolumn{1}{c}{ Assigned compounds } \\
\hline \hline 42 & Ketene \\
118 & Propenylbenzene/indane \\
120 & Propylbenzene
\end{tabular}

130

Methylindene

132

Methylindane

142

1-Methylnaphthalene

154

156

Ethylnaphthalene

166

168

180

Dihydrophenanthrene/methyl $1 \mathrm{H}$-benz[e]indene/methylyfluorene/

$1 \mathrm{H}$-phenalene/methylacenaphthylene/ $1 \mathrm{H}$-benz[e]indene

Methylbiphenyl/1-(2-propenyl) naphthalene/1H-benz[e]indane
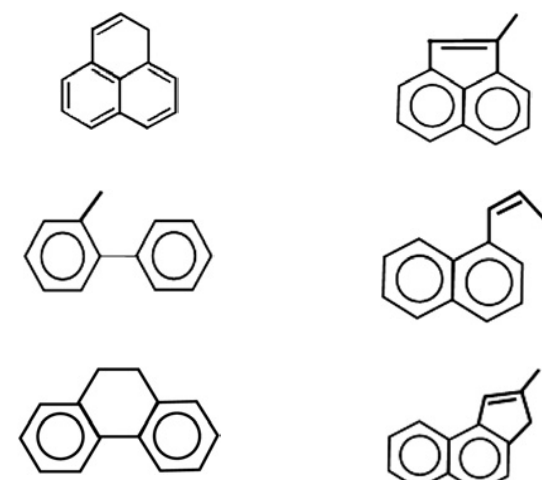<smiles>C1=Cc2c(ccc3ccccc23)C1</smiles><smiles>C/C=C\c1cccc2ccccc12</smiles><smiles>c1ccc2c3c(ccc2c1)CCC3</smiles>

182

190

4H-cyclopenta[def]phenanthrene

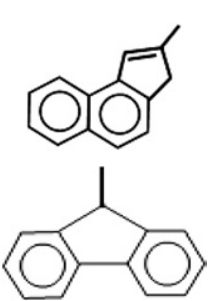

$\langle\longrightarrow$

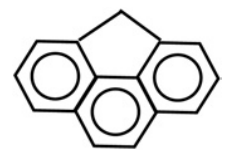


Table 1. Continued

\begin{tabular}{|c|c|c|c|}
\hline \multirow{4}{*}{\multicolumn{2}{|c|}{$m / z$}} & & \\
\hline & & & \\
\hline & & & \\
\hline & & & \\
\hline & & 206 & Ethylphenanthrene \\
\hline & & 216 & Methylpyrene \\
\hline & & 218 & Methyldihydropyrene \\
\hline & & & \\
\hline & & & \\
\hline & & & \\
\hline & & & Methylphenanthrene \\
\hline & & 194 & Methyldihydrophenanthrene \\
\hline & & 204 & $\begin{array}{l}\text { Dihydropyrene/methyl-4H- } \\
\text { cyclopenta[def]phenanthrene }\end{array}$ \\
\hline & & 206 & \\
\hline & & & \\
\hline & & 218 & \\
\hline & & 226 & Cyclopenta[cd]pyrene \\
\hline & & 228 & $\begin{array}{l}\text { Ethenylpyrene/3-4 } \\
\text { dihydrocyclopenta[cd]pyrene }\end{array}$ \\
\hline
\end{tabular}

Changes in Mass Spectra with Increasing Temperature

The most remarkable change observed in the mass spectra with increasing temperature was the appearance or enhancement of $-2 \mathrm{u}$ peaks with the loss of the neighboring higher mass number peaks in each bundle. This result suggests that the $-2 \mathrm{u}$ species are the dehydrogenated or dehydrocyclized products of the corresponding higher mass species. Figure 3 shows the temperature-dependent variations of the intensities of some important species. With increasing temperature, most of the toluene and all of the acetone reagents were found to be consumed, reflecting the greater rate for thermal decomposition of acetone (eqs 1a and 1b), over toluene (eqs $2 \mathrm{a}$ and $2 \mathrm{~b}$ ); through these decomposition reactions, the primary active species, $\mathrm{C}_{6} \mathrm{H}_{5} \mathrm{CH}_{2}$, $\mathrm{C}_{6} \mathrm{H}_{5}, \mathrm{H}$, and $\mathrm{CH}_{3}$, are produced,

$$
\begin{aligned}
& \mathrm{CH}_{3}-\mathrm{CO}-\mathrm{CH}_{3}+\mathrm{M} \rightarrow \mathrm{CH}_{3} \mathrm{COCH}_{2}+\mathrm{H}+\mathrm{M} \\
& \mathrm{CH}_{3} \mathrm{COCH}_{2} \rightarrow \mathrm{CH}_{2}=\mathrm{CO}+\mathrm{CH}_{3} \\
& \mathrm{C}_{6} \mathrm{H}_{5} \mathrm{CH}_{3}+\mathrm{M} \rightarrow \mathrm{C}_{6} \mathrm{H}_{5} \mathrm{CH}_{2}+\mathrm{H}+\mathrm{M} \\
& \mathrm{C}_{6} \mathrm{H}_{5} \mathrm{CH}_{3}+\mathrm{M} \rightarrow \mathrm{C}_{6} \mathrm{H}_{5}+\mathrm{CH}_{3}+\mathrm{M}
\end{aligned}
$$

At low-temperature $(1140 \mathrm{~K})$ when acetone was added to toluene, there was significant enhancement in the 


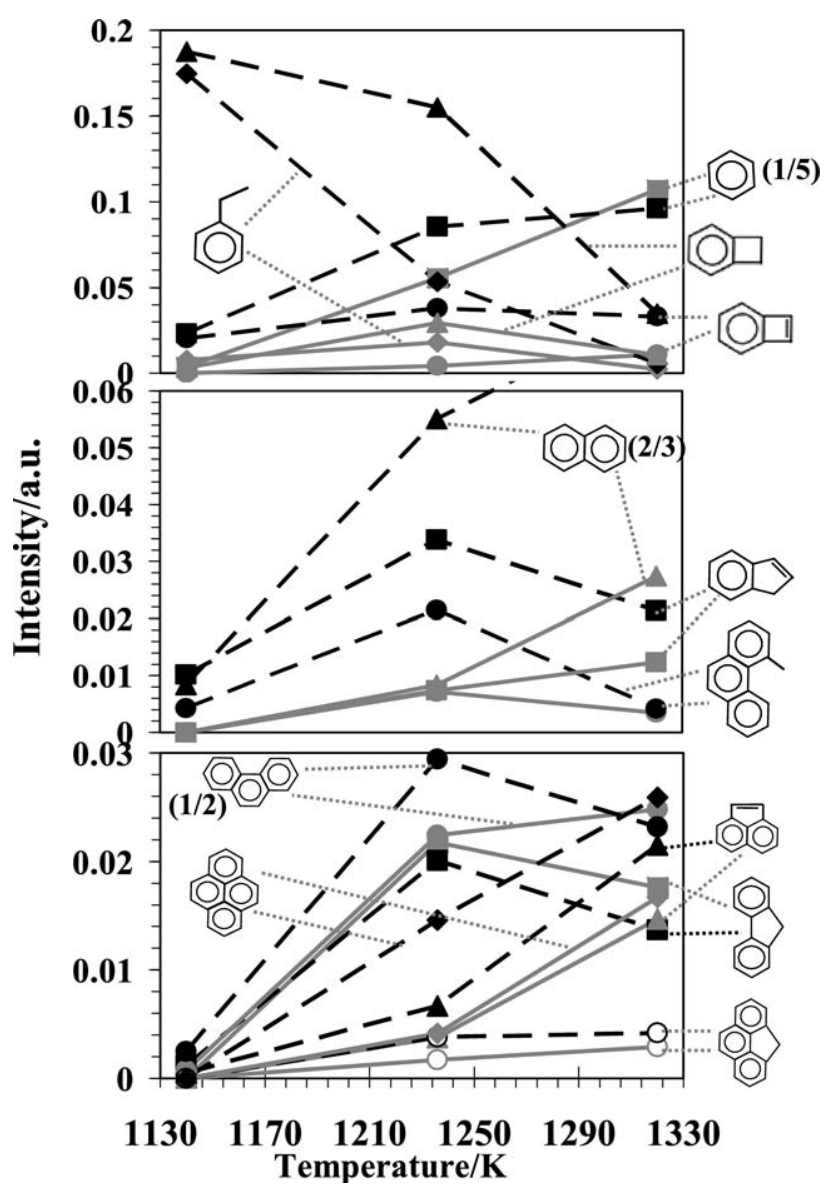

Figure 3. Temperature-dependent variation of signal intensities of some important species. Bold lines represent products from pure toluene $(100 \%)$ and dotted lines represent products from the toluene/acetone mixture (1:1).

peaks for ethylbenzene $(\mathrm{m} / \mathrm{z}=106)$ and its derived products, as well as loss of bibenzyl $(m / z=182)$; in addition, some aliphatic products at $\mathrm{m} / \mathrm{z}<78$ and aromatic products at $m / z=116,118,120,128,130,132$, 142, 190, 192, 196, 204, and 206 were also observed. Detection of these species upon addition of acetone, a major source of methyl radicals, suggests that they are either methyl substituted species or their derived products. At $1236 \mathrm{~K}$, the appearance of many new species, especially at higher masses, enhancement in cyclization products $(-2 \mathrm{u}$ peaks), and the significant decrease of ethylbenzene $(\mathrm{m} / \mathrm{z}=106)$ and styrene or bicyclo[4.2.0]octa-1,3,5-triene $(\mathrm{m} / \mathrm{z}=104)$, are remarkable. At $1320 \mathrm{~K}$, there is a sharp decrease in concentrations of most species; however, enhancement in the production of naphthalene and pyrene, as shown in the middle and bottom frames of Figure 3, reflects their higher rates of production with lower rates of consumption by methyl radicals.

\section{Discussion}

The mass spectrum of acetone at room-temperature was measured and is shown in Figure 4. This spectrum clearly shows the negligible effect of photolysis of acetone in the present study, similar to the results of Mullen et al. [28] and Wei et al. [29a]. These results indicate that all observed products are the result of bimolecular reactions caused by thermal decomposition of toluene and acetone.

On addition of acetone to toluene, the significant enhancement in the intensity of ethylbenzene $(\mathrm{m} / \mathrm{z}=$ $\left.106, \mathrm{C}_{6} \mathrm{H}_{5} \mathrm{C}_{2} \mathrm{H}_{5}\right)$, which is the product of benzyl $\left(\mathrm{C}_{6} \mathrm{H}_{5} \mathrm{CH}_{2}\right)+$ methyl $\left(\mathrm{CH}_{3}\right)$, and the depletion of bibenzyl $(\mathrm{m} / \mathrm{z}=182)$, which is the product of benzyl $\left(\mathrm{C}_{6} \mathrm{H}_{5} \mathrm{CH}_{2}\right)+$ benzyl $\left(\mathrm{C}_{6} \mathrm{H}_{5} \mathrm{CH}_{2}\right)$, reflects the higher rates of production of methyl radical (eqs $1 \mathrm{~b}, 2 \mathrm{~b}$ ) than that of benzyl radical (eq 1a). On the basis of the rapid quenching of benzyl radical by the methyl radical to form ethylbenzene, this result also indicates that the radical recombination reaction (eq 3 ) is faster than that of (eq 4), which may be due to the smaller size and higher reactivity of methyl radicals.

$$
\begin{aligned}
& \mathrm{C}_{6} \mathrm{H}_{5} \mathrm{CH}_{2}+\mathrm{CH}_{3} \rightarrow \mathrm{C}_{6} \mathrm{H}_{5} \mathrm{CH}_{2} \mathrm{CH}_{3} \\
& \mathrm{C}_{6} \mathrm{H}_{5} \mathrm{CH}_{2}+\mathrm{C}_{6} \mathrm{H}_{5} \mathrm{CH}_{2} \rightarrow \mathrm{C}_{6} \mathrm{H}_{5} \mathrm{CH}_{2} \mathrm{CH}_{2} \mathrm{C}_{6} \mathrm{H}_{5}
\end{aligned}
$$

The change in major pyrolysis products from pure toluene to the mixture especially at low-temperature (i.e., benzene to ethylbenzene, top frame of Figure 3) suggests that the chain carrier $\mathrm{H}$, which produces benzene by (eq 5) in the toluene pyrolysis, reacts with acetone (eq 6) in the toluene/acetone mixture to accelerate reaction (eq $1 \mathrm{~b}$ ); this process results in the rapid decomposition of acetone to produce methyl radicals.

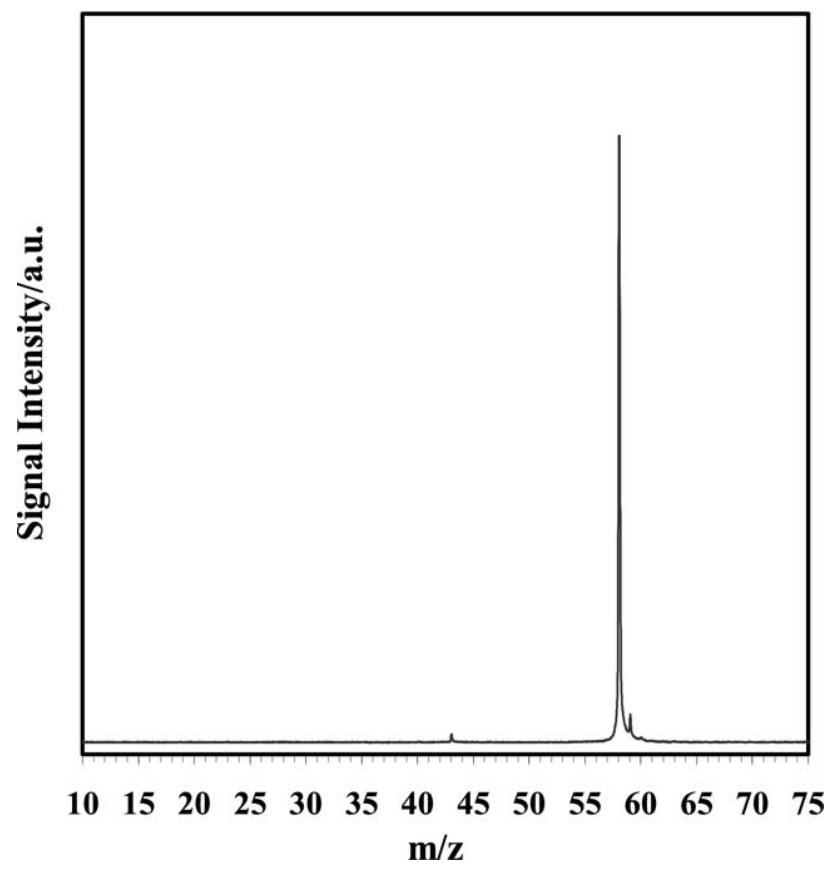

Figure 4. TOF mass spectra of acetone at room temperature 298 $\mathrm{K}$, which shows the negligible fragmentation caused by laser photolysis. 


$$
\begin{aligned}
& \mathrm{C}_{6} \mathrm{H}_{5} \mathrm{CH}_{3}+\mathrm{H} \rightarrow \mathrm{C}_{6} \mathrm{H}_{6}+\mathrm{CH}_{3} \\
& \mathrm{CH}_{3}-\mathrm{CO}-\mathrm{CH}_{3}+\mathrm{H} \rightarrow \mathrm{CH}_{3} \mathrm{COCH}_{2}+\mathrm{H}_{2}+\mathrm{M}
\end{aligned}
$$

The occurrence of ion sequences with an interval of $14 \mathrm{u}$ results from $\mathrm{H}$-atom abstraction $(-1 \mathrm{u})$ followed by $\mathrm{CH}_{3}$ radical addition $(+15 \mathrm{u})$. Another interesting series is the appearance of one to three additional peaks that sequentially appear at $2 \mathrm{u}$ lower than the dominant peak; these ions dominate at high temperatures with simultaneous loss of the higher mass peaks. These experimental facts clearly suggest the following formation and successive conversion routes:

1. The probable candidates for the $14 \mathrm{u}$ interval peaks from stable species such as benzene (e.g., $m / z=92$, 106, 120), are methyl, ethyl/dimethyl and propyl/ ethylmethyl-derivatives, respectively. The presence of dimethyl or ethylmethyl-derivatives, rather than their isomers, ethyl and propyl-derivatives, is unlikely due to steric hindrance in the ortho derivatives; moreover, the meta and para derivatives cannot readily form dehydrogenated or dehydrocyclized products ( $-2 \mathrm{u}$ peaks).

2. Generally in each bundle of peaks, the appearance or dominance of the $-2 \mathrm{u}$ peaks at high temperatures indicates the formation of stable cyclization products, such as externally fused CT-PAHs, CPPAHs, and primary PAHs as a result of dehydrocyclization of alkyl-PAHs because of their thermal instabilities.

On the basis of these results for the observed sequential mass spectra, kinetic mechanisms for the formation of detected species are discussed below.

\section{Kinetics of the Formation of CT and CP Fused Aromatic Products and Primary PAHs}

It is interesting to note that the observed unique sequences of mass peaks at repeating intervals of $14 \mathrm{u}$ have been found starting from mono-, di-, and tricyclic aromatic hydrocarbons. For example, those sequences started (1) from benzene $(m / z=78)$, with corresponding peaks at $m / z=92,106,120$, which are assigned to toluene, ethylbenzene, and propylbenzene produced by reaction (eq 7), (2) from naphthalene $(m / z=128)$, with corresponding peaks at $m / z=142,156$ (very weak) which are assigned to 1-methylnaphthalene and 1ethylnaphthalene produced by reaction (eq 8), and (3) from phenanthrene $(\mathrm{m} / \mathrm{z}=178)$ with corresponding peaks at $m / z=192,206$, which are assigned to methylphenanthrene and ethylphenanthrene produced by reaction (eq 9). Once again the main reason for assigning ethylbenzene, propylbenzene, 1-ethylnaphthalene and ethylphenanthrene as the identities for the mass peaks at $m / z=106,120,156$, and 206 instead of their dialkyl isomers, such as dimethylbenzene (xylene), ethylmethylbenzene, dimethylnaphthalene, and dimethylphenan- threne, is the steric hindrance between two alkyl groups at ortho positions; moreover, the meta and para isomers cannot readily lose $2 \mathrm{u}$ by dehydrogenation/dehydrocyclization. The observation of these sequences suggests that the addition reaction of a methyl radical with an aromatic compound forming a side chain only proceeds until the formation of a propyl derivative, i.e., addition of three methyl radicals.

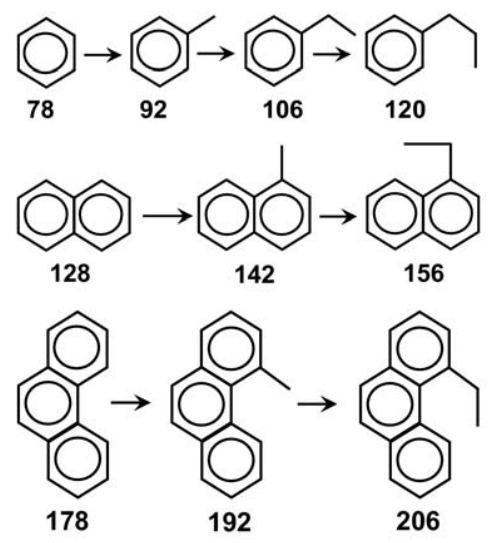

Each arrow in reactions (eqs 7-9) represents $\mathrm{H}$-atom abstraction $(-\mathrm{H})$ followed by methyl radical addition $\left(+\mathrm{CH}_{3}\right)$, and the numbers indicate the mass numbers of the species. These results indicate that the reaction of methyl radical with the side-chain of alkyl benzenes such as toluene [19-21] is faster than with the aromatic ring $[9,16-18]$. Interestingly, the appearance of the -2 $\mathrm{u}$ peaks especially for alkyl aromatic species clearly indicates that alkyl aromatic compounds have less thermal stability; they are frequently converted to their respective radicals that further adopt the stable cyclic structures by dehydrocyclization (eqs 10 and 11). For example, ethylnaphthalene is converted into acenaphthene through reactions (eqs 10 and 11).

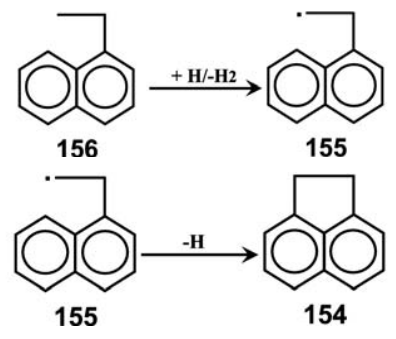

This expectation coincides with the previous prediction of Stein and Fahr [29b] that condensed PAHs are thermally more stable than alkyl-PAHs. On this basis, the most probable candidates for (1) the mass peaks at $m / z=104,118$ are bicyclo[4.2.0]octa-1,3,5-triene and indane produced by the reaction (eq 12), (2) the peaks at $m / z=140,154$ are cyclopropanaphthalene and acenaphthene produced by the reaction (eq 13), and (3) the peaks at $m / z=190,204$ are $4 \mathrm{H}$-cyclopenta[def]phenanthrene and 4,5-dihydropyrene produced by the reaction (eq 14). The main reason for considering these cyclic products 
instead of dehydrogenated products, alkenyl and alkynyl derivatives, is the further growth of the resulting products by additional methyl radicals; these processes might be difficult for alkenyl and alkynyl derivatives. The consecutive methyl products at $+14 \mathrm{u}$ will be discussed briefly in the following section (each arrow in reactions 12-14 represents dehydrocyclization $\left(-\mathrm{H}_{2}\right)$ following reactions (eqs 10 and 11).

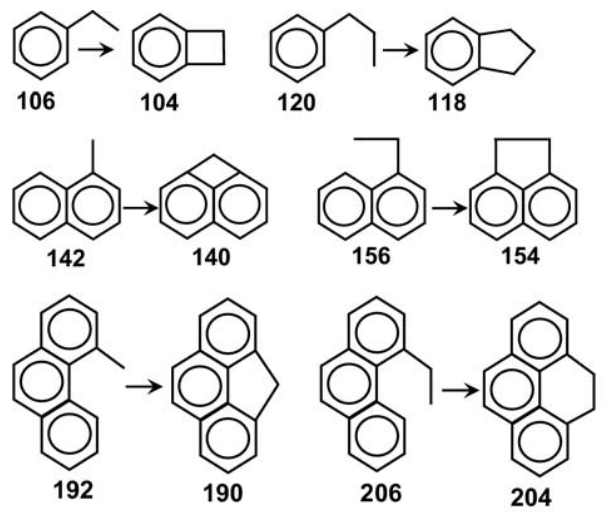

Moreover, mass peaks of species having $C_{2}$ or $C_{3}$ cyclic attachments as a result of the above reactions (eqs 12-14), were found to have a similar sequence of $-2 \mathrm{u}$ peaks. These peaks occur at $m / z=102,116,152$, and 202; they become dominant with increasing temperature as the higher mass peak is suppressed (Figure 1). Therefore, these ions are identified as the dehydrogenated products of the species resulting from reactions (eqs $12-14$ ). More clearly (1) $\mathrm{m} / \mathrm{z}=102,116$ are identified as bicyclo[4.2.0]octa-1,3,5,7-tetraene and indene; (2) $\mathrm{m} / \mathrm{z}=$ 152 is acenaphthylene, and (3) $m / z=202$ is pyrene. Their formation can be seen in reactions (eqs 15-17) in which each arrow represents dehydrogenation $\left(-\mathrm{H}_{2}\right)$.

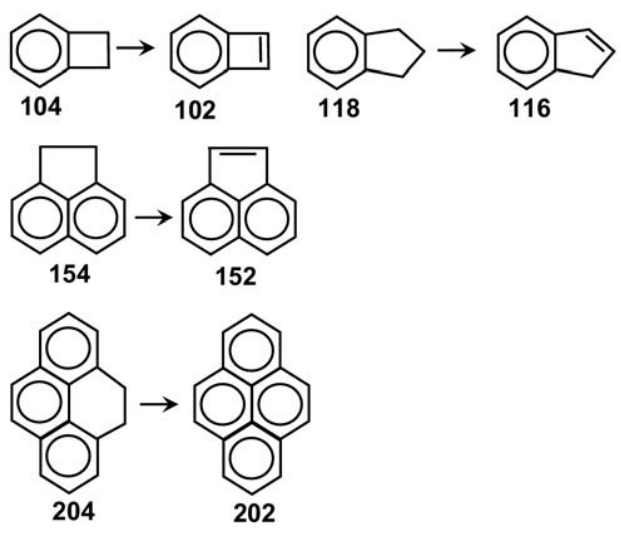

The above discussion is well supported by the increasing intensities of the final products, bicyclo[4.2.0]octa1,3,5,7-tetraene, indene, acenaphthylene, and pyrene $(m / z=102,116,152$, and 202) relative to their parent species ethylbenzene, propylbenzene, and phenanthrene (except naphthalene, Figures 1 and 2 in the case of the mixture). This discussion suggests the impor- tance of methyl addition/cyclization (MAC) processes in the growth of PAHs. The cause of the significant enhancement in the naphthalene concentration will be discussed in the following section. Figure 2 shows the higher concentration of phenanthrene $(m / z=178)$ in the mixture than in pure toluene even though it is consumed for the formation of pyrene by reactions (eqs 14 and 17). There is a relatively lower contribution of biphenyl at $m / z=154$ (Figures 1 and 2) in the case of the mixture than in pure toluene, and the sequential mass growth peaks at $m / z=168,182$ are also weaker than in pure toluene. These weak peaks relative to the strong peak at $m / z=178$ explain the formation of phenanthrene $(m / z=178)$ via reaction (eq 18), similar to reactions (eqs 14 and 17), since biphenyl also has a triple fusing site as does phenanthrene.

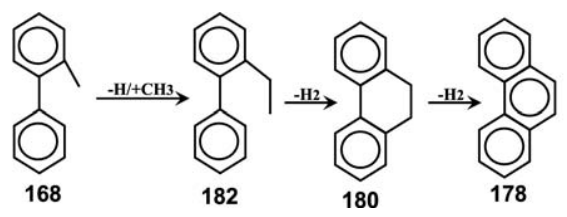

Considering the contribution of benzylbenzene at $\mathrm{m} / \mathrm{z}=$ 168 due to the presence of toluene in the mixture and its neighboring strong peak at $\mathrm{m} / \mathrm{z}=178$, formation of anthracene, an isomer of phenanthrene $(\mathrm{m} / \mathrm{z}=178)$, can also be expected by MAC through reaction (eq 19).

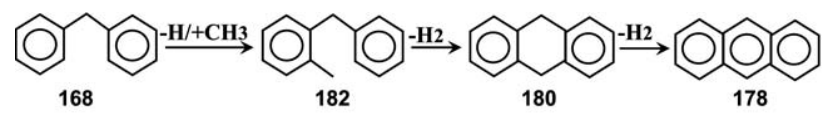

Similar to the peak assignments and formation pathways (eq 13) and (eq 16) for products formed from naphthalene, a PAH with double fusing sites, the assignment and growth process for masses $m / z=218$ and 216 , which are $14 \mathrm{u}$ from $m / z=202$ (pyrene), can be easily understood. The appearance of rather weak peaks for the products of MAC with double fusing sites both in the case of naphthalene and pyrene, even though the concentrations of both starting species are quite high (Figure 3), suggests that the MAC process with double fusing sites is rather slow compared with single and triple fusing sites.

\section{Kinetics of Ring Expansion: CT- and CP-Fused Rings into Benzenoid Ring}

These experimental results do not provide direct evidence for the significant production of naphthalene in spite of its consumption through reaction (eq 13); however, the data suggest the growth of indene into naphthalene by the MAC/ring expansion via reaction (eq 20). Figure 1 shows the presence of $m / z=130$ that is $14 \mathrm{u}$ above $m / z=116$ (indene), as well as the dehydrogenation sequence ending in naphthalene $(\mathrm{m} / z=128)$. 
Moreover, the percentage decrease in intensity of indene above $1236 \mathrm{~K}$ is equivalent to the percentage increase in intensity of naphthalene $(\sim 36 \%$ middle frame of Figure 3).

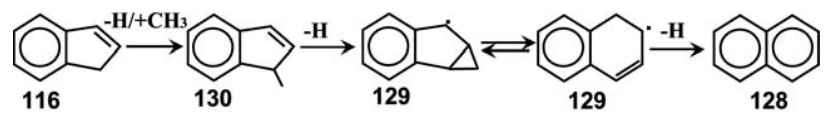

(20)

Due to the presence of toluene in the mixture, contributions to the formation of naphthalene from benzyl + $\mathrm{C}_{3} \mathrm{H}_{3}$ as well as phenylacetylene $+\mathrm{C}_{2} \mathrm{H}_{2}$ cannot be overlooked; however, considering the lower concentrations of benzyl, $\mathrm{C}_{3} \mathrm{H}_{3}$, and $\mathrm{C}_{2} \mathrm{H}_{2}$ in the reaction mixture, the rate of production by reaction (eq 20) is likely higher than for the other possibilities.

Similarly, significant production of indene $(\mathrm{m} / \mathrm{z}=$ 116) through reactions (eq 12) and (eq 15) alone seems unlikely from the correlation of the percentage decrease in intensity of its consecutive 2 u peaks at $m / z=118,120$ and of the increase in intensity of indene. On the other hand, significant decrease in concentration of bicyclo[4.2.0]octa-1,3,5-triene $(m / z=104)$ with consistency in the production of its derived dehydrogenated product, bicyclo[4.2.0]octa-1,3,5,7-tetraene $(\mathrm{m} / \mathrm{z}=102)$ at high-temperature (top frame of Figure 3) clearly indicate that bicyclo[4.2.0]octa-1,3,5,7-tetraene must be consumed for producing a new product. On the basis of the exact $14 \mathrm{u}$ difference of indene from a CT fused species bicyclo[4.2.0]octa-1,3,5,7-tetraene $(m / z=102)$, a secondary source for the production of indene from bicyclo[4.2.0]octa-1,3,5,7-tetraene by MAC through ring expansion via reaction (eq 21) can be reasonably expected.

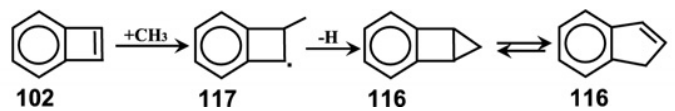

For this specific case, methyl radical addition followed by cyclization resulting in ring expansion has also been reported by McEnally et al. [30, 31] and Lifshitz et al. [32]. In the discussion above, it is found that most of the final species in a vertical column in Scheme $\mathbf{1}$ involve a network of $\mathrm{sp}^{2}$ carbons. The absence of very large PAHs in this study might be due to the following reasons:

1. Since the reactivity of large PAHs with methyl radical increases with size [32, 33], their higher reactivity might be accelerating the sequential growth of increasingly larger species.

2. A continuation of the above chain causes rapid formation and consumption of products that might result in very low concentrations of large PAHs that lie below the detection limit. The appearance of higher mass species with increasing temperature in Figure 1 supports this expectation.

\section{Scope of MAC in Combustion and Growth of} CNTs and Graphene

The above kinetic pathways for product formation are summarized in Figure 5, which includes the formation of benzene to pyrene, primary PAHs, together with some CT-PAHs and CP-PAHs. This figure provides an overview of all possible routes for ring growth by the attack of one or more methyl radicals followed by cyclization. Since methyl radical is a highly reactive species and it is readily produced in combustion and pyrolysis of most hydrocarbons in addition to $C_{2}$ radi$\mathrm{cal} /$ neutral species, the suggested reaction flow diagram is expected to be useful for other pyrolysis and combustion environments as a secondary route to supplement the primary PAC and HACA mechanisms. Moreover, the methyl radical may play a role in the CVD growth of CNTs and graphene. Its special capacity to grow benzenoid rings from all fusing sites as well as to expand $\mathrm{CT}$ and $\mathrm{CP}$ fused rings produced by the addition of $\mathrm{C}_{2}$ and $\mathrm{C}_{3}$ radical/neutral species to hexagonal networks of $\mathrm{sp}^{2}$ carbons might protect the formation of CT and CP rings in graphitic structured materials like CNTs and graphene. The MAC process can be summarized as

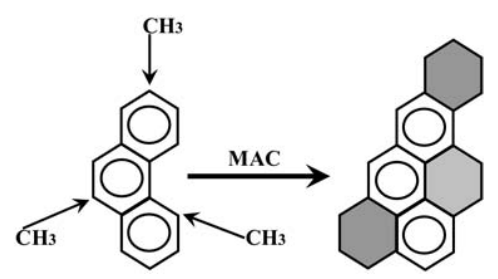

\section{Conclusions}

The above kinetic discussion of experimental results for toluene and toluene/acetone mixtures can be summarized as follows:

1. A novel growth mechanism for PAHs, methyl addition/cyclization (MAC), has been proposed.

2. The MAC mechanism was found to be capable of growing the $\mathrm{sp}^{2}$ network of carbons from any fusing site of a PAH, as well as growing CT and CP-PAH into benzenoid PAHs.

3. The MAC mechanism is not as efficient as HACA or $\mathrm{PAC}$ in the rate of growth of PAHs; this results from the lower mass of the accelerating species, $\mathrm{CH}_{3}$ for MAC, relative to $\mathrm{C}_{2} \mathrm{H}_{2}$ for HACA and $\mathrm{C}_{6} \mathrm{H}_{5}$ for PAC.

4. Many methyl-PAHs, CT-PAHs, CP-PAHs, methylCPPAHs, and large PAHs were produced and detected.

5. Formation of three types of CP-PAHs indicates that cyclopentafused rings can be grown at single, double, and triple fusing sites; this mechanism has been discussed for systems where HACA and PAC mechanisms are inefficient. 


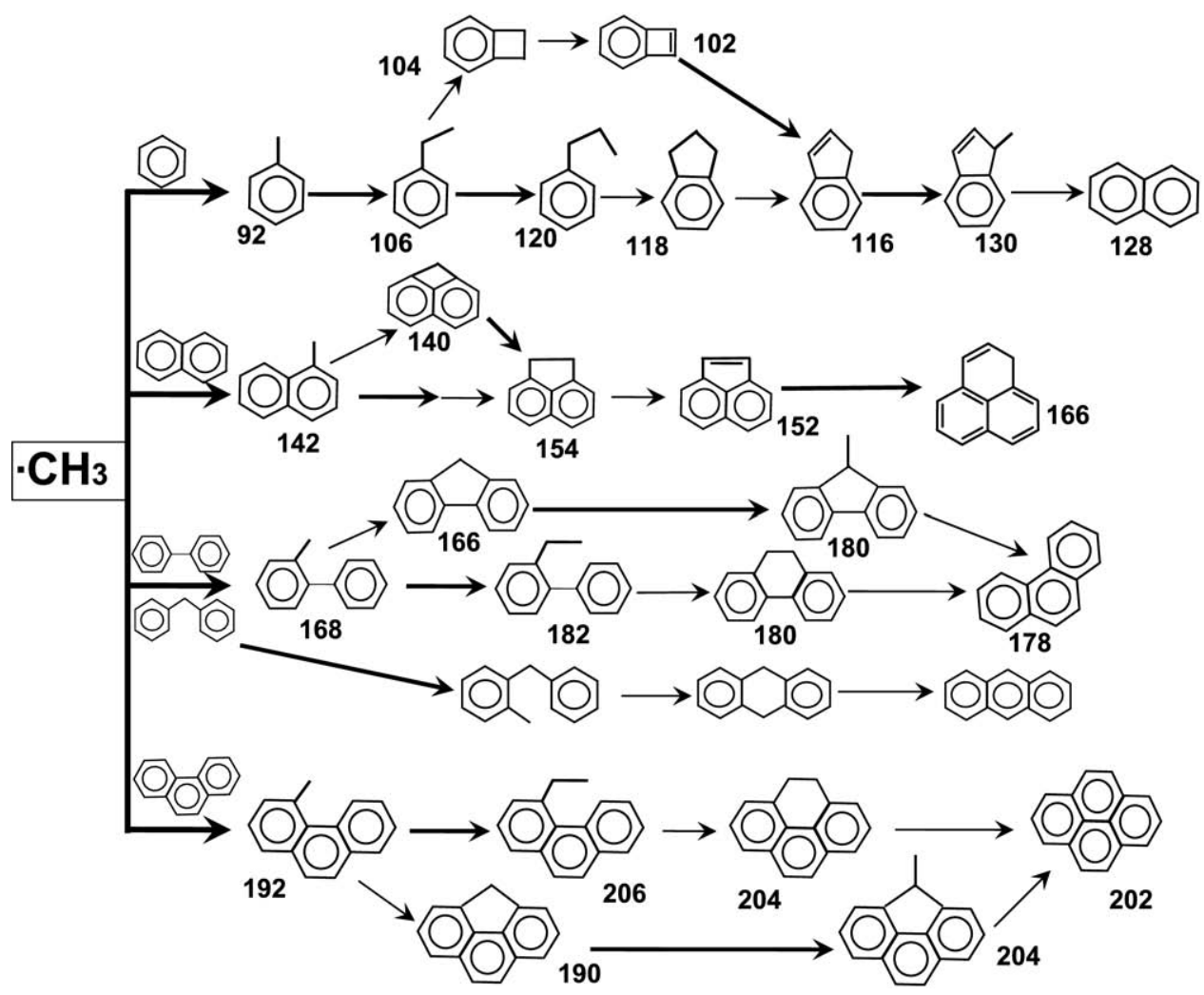

Figure 5. Detailed explanation of MAC reaction routes showing the reaction of methyl radical with different fusing sites of a PAH, CT-PAH, and CP-PAHs. Bold arrows indicate hydrogen abstraction followed by methyl addition while thin arrows represent dehydrogenation or dehydrocyclization. Numbers are the mass numbers of the corresponding species.

6. Abstraction of hydrogen from a side chain with further addition of methyl radical was found to be preferable over hydrogen atom abstraction by methyl radical from the aromatic ring of alkyl aromatic compounds such as toluene.

\section{Acknowledgments}

B.S. thanks Professor Veronica Bierbaum for her editorial assistance and Takeshi Saito for communication about this manuscript. This work was completed in the Department of Chemical System Engineering, University of Tokyo, during the Ph.D. studies of B.S.

\section{References}

1. Shukla, B.; Susa, A.; Miyoshi, A.; Koshi, M. In Situ Direct Sampling Mass Spectrometric Study on Formation of Polycyclic Aromatic Hydrocarbons in Toluene Pyrolysis. J. Phys. Chem. A 2007, 111(34), 8308-8324.

2. Wang, H.; Frenklach, M. A Detailed Kinetic Modeling Study of Aromatics Formation in Laminar Premixed Acetylene and Ethylene Flames. Combust. Flame 1997, 110, 173-221.

3. Frenklach, M.; Clary, D. W.; Gardiner, W. C.; Stein, S. E. Detailed Kinetic Modeling of Soot Formation in Shock-Tube Pyrolysis of Acetylene. Proc. Combust. Inst. 1985, 20, 887-901.

4. Frenklach, M.; Wang, H. Detailed Modeling of Soot Particle Nucleation and Growth Proc. Combust. Inst. 1991, 23, 1559-1566.

5. Bockhorn, H.; Fetting, F.; Wenz, H. W. Investigation of the Formation of High Molecular Hydrocarbons and Soot in Premixed HydrocarbonOxygen Flames. Ber. Bunsen-Ges. Phys. Chem. 1983, 87, 1067.

6. Böhm, H.; Jander, H.; Tanke, D. PAH Growth and Soot Formation in the Pyrolysis of Acetylene and Benzene at High Temperatures and Pressures: Modeling and Experiment. Proc. Combust. Inst. 1998, 27, 16051612.

7. McKinnon, J. T.; Howard, J. B. The Roles of PAH and Acetylene in Soot Nucleation and Growth. Proc. Combust. Inst. 1992, 24, 965-971.
8. Badger, G. M. Pyrolysis of Hydrocarbons. Prog. Phys. Org. Chem. 1965, 3(1), 1-40.

9. Badger, G. M.; Donnelly, J. K.; Spotswood, T. M. The Formation of Aromatic Hydrocarbons at High Temperatures. XXIII. The Pyrolysis of Anthracene. Aust. J. Chem. 1964, 17, 1147-1156.

10. Sarofim, A. F.; Longwell, J. P.; Wornat, M. J.; Mukherjee, J. In Soot Formation in Combustion-Mechanisms and Models, Bockhorn, H.; Ed.; Springer Series in Chemical Physics 59, Springer-Verlag: Heidelberg, Germany, 1994; pp 485-500.

11. Griesheimer, J.; Homann, K.-H. Large Molecules, Radicals, Ions, and Small Soot Particles in Fuel-Rich Hydrocarbon Flames. Part I. Aromatic Radicals and Intermediate PAHs in a Premixed Low-Pressure Naphthalene/Oxygen/Argon Flame. Proc. Combust. Inst. 1998, 27, 1753-1761.

12. Dong, G. L.; Huttinger, K. J. Consideration of Reaction Mechanisms Leading to Pyrolytic Carbon of Different Texture. Carbon 2002, 40, 2515-2528.

13. Unterreiner, V. B.; Sierka, M.; Ahlrichs, R. Reaction Pathways for Growth of Polycyclic Aromatic Hydrocarbons Under Combustion Conditions, a DFT Study. Phys. Chem., Chem. Phys. 2004, 6, 4377-4384.

14. (a) Shukla, B.; Susa, A.; Miyoshi, A.; Koshi, M. Role of Phenyl Radicals in the Growth of Polycyclic Aromatic Hydrocarbons. J. Phys. Chem. A 2008, 112(11), 2362-2369; (b) Shukla, B.; Koshi, M. A Highly Efficient Growth Mechanism of Polycyclic Aromatic Hydrocarbons. Phys. Chem., Chem. Phys. 2010, DOI:10.1039/B919644G.

15. Wellmann, R.; Böttcher, A.; Kappes, M.; Kohl, U.; Niehus, H. Growth of Graphene Layers on HOPG Via Exposure to Methyl Radicals. Surf. Sci. 2003, 542, 81-93.

16. Cher, M. The Reaction of Methyl Radicals with Toluene. J. Phys. Chem. 1964, 68, 1316-1321.

17. Levy, M.; Szwarc, M. The Kinetics of Decomposition of Acetyl Peroxide. III. The Reactions of Radicals Produced in the Decomposition. J. Am. Chem. Soc. 1954, 76, 5981-5985.

18. Meyer, R. A.; Burr, J. G. The Hydrogen Carrier Technique for The Pyrolysis of Toluene and Deuterated Toluenes. J. Am. Chem. Soc. 1963, $85,478-479$.

19. Trotman-Dickenson, A. F.; Steacie, E. W. R. The Reactions of Methyl Radicals. IV. The Abstraction of Hydrogen Atoms from Cyclic Hydrocarbons, Butynes, Amines, Alcohols, Ethers, and Ammonia. J. Chem. Phys. 1951, 19, 329-336. 
20. Burkley, I. B.; Robbert, R. E. The Reactions of Methyl Radicals with Aromatic Compounds, Toluene, Ethylbenzene, and Cumene. J. Phys. Chem. 1963, 67, 168-169.

21. Cher, M.; Hollingsworth, C. S.; Sicilio, F. The Vapor Phase Reaction of Methyl Radicals with Toluene at 100-300'. J. Phys. Chem. 1966, 70(3), 877-883.

22. Unterreiner, V. B.; Carissan, Y.; Klopper, W. Density Functional Study of Methyl Chemisorption on Polycyclic Aromatic Hydrocarbons. Chem. Phys. Chem. 2006, 7, 1311-1321.

23. Grujicic, M.; Cao, G.; Gersten, B. Optimization of the Chemical Vapor Deposition Process for Carbon Nanotubes Fabrication. Appl. Surf. Sci. 2002, 191, 223-239.

24. Kong, J.; Cassel, A. M.; Dai, H. Chemical Vapor Deposition of Methane for Single-Walled Carbon Nanotubes. Chem. Phys. Lett. 1998, 292, 567-574.

25. Colomer, J. F.; Stephan, C.; Lefrant, S.; Van Tendeloo, G.; Willems, I.; Kónya, Z.; Fonseca, A.; Laurent, C; Nagy, J. B. Large-Scale Synthesis of Single-Wall Carbon Nanotubes by Catalytic Chemical Vapor Deposition (CCVD) Method. Chem. Phys. Lett. 2000, 317, 83-89.

26. Reina, A.; Jia, X.; Ho, J.; Nezich, D.; Son, H.; Bulovic, V.; Dresselhaus, M. S.; Kong, J. Large Area Few-Layer Graphene Films on Arbitrary Substrates by Chemical Vapor Deposition. Nano Lett. 2009, 9(1), 30-35.

27. Kim, K. S.; Zhao, Y.; Jang, H.; Lee, S. Y.; Kim, J. M.; Kim, K. S.; Ahn, J. H.; Kim, P.; Choi, J. Y.; Hong, B. H. Large-Scale Pattern Growth of
Graphene Films for Stretchable Transparent Electrodes, Nature Lett. 2009, 457, 706-710.

28. Mullen, C.; Irwin, A.; Pond, B. V.; Huestis, D. L.; Coggiola, M. J.; Oser, H. Detection of Explosives and Explosive Related Compounds (ERCs) by Single Photon Laser Ionization Time of Flight Mass Spectrometry. Anal. Chem. 2006, 78, 3807-3814.

29. (a) Wei, L.; Yang, B.; Yang, R.; Huang, C.; Wang, J.; Shan, X.; Sheng, L.; Zhang, Y.; Qi, F.; Lam, C.-S.; Li, W.-K. A Vacuum Ultraviolet Photoionization Mass Spectrometric Study of Acetone. J. Phys. Chem. A 2005, 109 4231-4242; (b) Stein, S. E.; Fahr, A. High-Temperature Stabilities of Hydrocarbons. J. Phys. Chem. 1985, 89, 3714-3725.

30. McEnally, C. S.; Pfefferle, L. D. An Experimental. Study in NonPremixed Flames of Hydrocarbon Growth Processes That Involve Five-Membered Carbon Rings. Combust. Sci. Technol. 1998, 131, 323-344.

31. McEnally, C. S.; Pfefferle, L. D. Improved Sooting Tendency Measurements for Aromatic Hydrocarbons and Their Implications for Naphthalene Formation Pathways. Combust. Flame 2007, 148, 210-222.

32. Lifshitz, A.; Tamburu, C.; Suslensky, A.; Dubnikova, F. Decomposition, Isomerization, and Ring Expansion in 2-Methylindene: Single-Pulse Shock Tube and Modeling Study. J. Phys. Chem. A 2004, 108, 3430-3438.

33. Levy, M.; Szwarc, M. Methyl Affinities of Aromatic Hydrocarbons. J. Chem. Phys. 1954, 22, 1621-1623. 